\title{
Clinical pattern and prevalence of rheumatic diseases among adults: a community-based cross-sectional study in rural Gadchiroli, India
}

Vinay R Joshi', Anand A Bang ${ }^{2}$, Shekhar Y Bhojraj ${ }^{3}$, Mahesh Deshmukh², Tushar Yarmal', Sameer Kalkotwar ${ }^{3}$, Raghu Varma ${ }^{3}$, Yogeshwar V Kalkonde², Abhay T Bang ${ }^{2}$

1 Hinduja Hospital and Research Center, Mumbai, Maharashtra, India, 2 Society for Education, Action and Research in Community Health (SEARCH), Gadchiroli, Maharashtra, India, ${ }^{3}$ Spine Foundation, Mumbai, Maharashtra, India, 4 Naraindas Morbai Budhrani Trust, Mumbai, Maharashtra, India Keywords: india, musculoskeletal pain, rheumatic diseases, prevalence

https://doi.org/10.29392/001c.22240

\section{Journal of Global Health Reports}

Vol. 5, 2021

\section{Background}

Population-level information on the prevalence of rheumatic disorders from rural India is rare. We investigated the prevalence and patterns of rheumatic disorders among adults in rural Gadchiroli, India.

\begin{abstract}
Methods
In this population-based, cross-sectional study, trained surveyors conducted a door-to-door survey to identify individuals with pain in back and extremities in two randomly selected villages from this region. Subjects who reported the presence of pain were evaluated by a team of a rheumatologist and orthopedic surgeons in a special clinic organized in these villages.
\end{abstract}

\section{Results}

Out of 2,535 eligible adults, 2,259 (89\%) were surveyed, and 1,247 (55\%) reported pain in the back or the extremities, and were therefore referred to the specialist clinic. Out of 884 (71\%) participants who attended the clinics, 615 (70\%) reported pain in the extremities. The point prevalence of soft tissue rheumatism (STR) in the community was $28 \%$ (95\% confidence interval, $\mathrm{CI}=26.1-29.8 \%)$ while that of arthritis was $12.2 \%(10.8-13.5)$. The point prevalence of rheumatoid arthritis was $0.4 \%(0.1-0.6)$. Both STR and arthritis were more common in women and in the elderly.

\section{Conclusions}

Soft tissue rheumatism was the commonest rheumatic disorder in this rural community, followed by arthritis. Inflammatory and infectious disorders were rare. Given the high prevalence of STR and arthritis, community health workers and physicians working in rural areas need to be trained, in order to improve the management of these conditions.

Musculoskeletal disorders are the leading global cause of disability. ${ }^{1-3}$ Collectively, they accounted for close to half (48\%) of all years of life lived due to disability from various diseases in 2019. ${ }^{4}$ Despite this, many regions of the world still lack population-level data on these disorders. ${ }^{5}$ In particular, data from rural populations are very limited. Available studies show that a significant proportion of rural population can be affected by musculoskeletal disorders. In a study from rural Iran $66 \%$ of adults reported musculoskeletal pain in the week preceding survey. ${ }^{6}$ As much as $61 \%$ of adults from rural Guatemala reported musculoskeletal complaints. Populations from Asia reported somewhat lower estimates; $26.2 \%$ in rural Bangladesh and $23.6 \%$ in Indonesia reported musculoskeletal pain. ${ }^{7-9}$

One sixth of the world's population lives in India, and more than two-thirds of the entire population of India lives in rural areas. ${ }^{10} \mathrm{~A}$ few population-based studies have been conducted in rural India to assess the prevalence of rheumatic disorders and other musculoskeletal complaints. However, these have been conducted in relatively affluent or peri-urban rural areas, ${ }^{11,12}$ while studies from rural agrarian communities in India are very rare. This is of the special interest, as these populations are even more likely to experience substantial burden of rheumatic disorders, as manual labour is the main source of income.

The aim of this study was to investigate the prevalence and patterns of rheumatic disorders among adults in rural Gadchiroli, which is one of the most underdeveloped districts of India. 


\section{METHODS}

\section{STUDY SETTING}

The study was conducted in Gadchiroli district of the Maharashtra state of India. The total population of the district is $1,071,795$ as per the National census conducted in $2011 .^{13}$ $93 \%$ of the district's population lives in rural areas and close to $75 \%$ of the land is covered by forest. ${ }^{13}$ The main source of livelihood is paddy cultivation. There is very little mechanization in farming activities, meaning that most of adults are extensively involved in paddy plantation, de-weeding and harvesting; the burden is even greater in women, who are additionally expected to attend their household chores such as collecting firewood, cooking, fetching drinking water from wells and washing clothes. Typically, only one crop is cultivated in a year and for the remaining part of the year adults are involved in forest labour, construction work in nearby towns, migrate for farm labour to neighbouring districts or participate in manual labour activities involved in constructing roads, digging wells and other water bodies under the employment guarantee scheme of the Government of India. ${ }^{14}$ There are no large-scale industries in the district. The district is classified as one of the most underdeveloped hundred districts of India by the NITI Aayog, the policy think tank of the central government. ${ }^{15}$

Health care in the district is provided primarily through the public health system. In addition, a few non-government organizations, traditional healers, unregistered informal providers, private registered practitioners also provide health care.

Society for Education, Action and Research in Community Health (SEARCH) is a non-governmental organization working in this district since 1986. It has a field practice area of 86 villages where community health workers (CHWs) regularly collect population-based information and provide health care for selected ailments. The study was jointly conducted by SEARCH, the Spine Foundation, a non-profit organisation to promote spine care in India and the rheumatology section of the Hinduja Hospital, a large tertiary care hospital in Mumbai, India.

\section{STUDY DESIGN AND SAMPLE}

This population-based, cross-sectional study was conducted in rural Gadchiroli. The sample size required for the study was calculated using the formula $\mathrm{Z}^{2}{ }_{1-\alpha / 2} \mathrm{P}(1-\mathrm{P}) / \mathrm{d}^{2}$ where $P$ is the anticipated prevalence of back pain and $d$ is the precision. ${ }^{16}$ Considering the anticipated point prevalence of non-specific low back pain in the adults $(\geqslant 20$ years of age) at $15 \%$, precision of 0.02 , design effect of $25 \%$ and a non-response rate of $15 \%$, a minimum sample of 1800 adults was needed. Considering the average population of adults in villages in the field practice area of SEARCH at about 1000, 2 villages were needed to be included in the study.

Out of 86 villages in the field practice area of SEARCH, in 39 villages the CHWs provide care for selected ailments. The two study villages were selected by a two-stage procedure from the sampling frame of 39 villages. The inclusion criteria for villages were- a) presence of residential male and female $\mathrm{CHW}$ of SEARCH in the village to ensure complete data collection, b) adult ( $\geqslant 20$ years) population $\geqslant 1000$, c) location more than $5 \mathrm{~km}$ away from Gadchiroli town, and d) no hospital or Primary Health Centre (PHC) located inside the village. The aim was to include typical Indian villages of medium size, not too close to an urban area, and where a house to house survey was feasible by the CHWs of SEARCH. Villages with larger adult population (>2000) were excluded. Seven villages out of 39 villages met the eligibility criteria. From these seven villages, two villages were randomly selected. The two selected villages, Mudza and Bamhani were 7 and 12 kilometers from the district headquarter respectively and 20 kilometers from each other. Both the villages were agrarian with farming as the primary source of livelihood. All the resident adults $\geqslant 20$ years of age of these two villages as recorded in the population register of SEARCH were eligible for the study and were recruited through household survey by the CHWs.

\section{DATA COLLECTION}

The study was conducted in two phases. In the first phase, data on point prevalence of pain in back and extremities were collected from $1^{\text {st }}$ January 2010 to $25^{\text {th }}$ January 2010 by the trained CHWs of SEARCH. The CHWs conducted a door to door survey and after taking an informed consent, administered the questionnaire to the eligible adults. All patients with pain in back and extremities were referred to a specialist clinic that was organized in these two villages, staffed by a team of a senior rheumatologist, spine surgeons, physiotherapists, occupational therapists and a psychologist.

In the second phase, patients referred by the CHWs were evaluated in a specialist clinic. The clinics were organized in respective villages approximately 15 days after the completion of the data collection for the prevalence study, in order to reduce the time lag between identification of symptoms (pain in back and extremities) by the CHW and the subsequent examination by the clinicians. This was also done to reduce possible inconsistencies in the findings of the CHWs and the clinician attributed to the time elapsed between the two visits.

We developed a survey instrument that was used in the clinic, focusing on medical history and musculoskeletal status. The survey instrument was pilot tested in a rheumatology clinic in the city of Mumbai, as well as in the rural clinic of SEARCH. Clinicians were trained to use the survey instrument in a standardized manner.

\section{DIAGNOSIS AND CLASSIFICATION}

The diagnoses were based on clinical examinations. Standard operational definitions based on the American College of Rheumatology 1990 criteria for diagnosing rheumatological diseases were used for various clinical diagnoses to ensure uniformity in diagnosis by the clinicians. ${ }^{17}$ Laboratory and imaging investigations were performed as necessary. The patients were managed according to the standard management plan. Further course of action was explained to patients in case there was no relief or if chronic treatment was deemed necessary. 


\section{STATISTICAL ANALYSES}

The information on the age- and sex-distribution of the population of the two villages was obtained from the population register of SEARCH. Age-specific prevalence rates of various rheumatological disorders were estimated for male and female clinic-attendees. Then the number of males and females in each age-group in the clinic non-attendee population were multiplied by these rates to obtain the expected number of cases for the clinic non-attendees using the method of indirect standardization. ${ }^{18,19}$ The number of cases for each rheumatological disorder from the attendee population and the expected number of cases from the nonattendee population were then combined to obtain the prevalence of that disorder in the entire adult population. We calculated $95 \%$ confidence intervals (CI) for the prevalence rates. Means were compared using Student's $t$ test and proportions were compared using Chi-square test. Analyses were conducted using Stata 10.0 (State Corp, College Station, Texas, USA), with significance set at $P<0.05$.

\section{ETHICS APPROVAL}

The study followed the tenets of the Declaration of Helsinki. Ethical approval for this study was granted as part of the main study to evaluate the prevalence of pain in back and extremities in rural Gadchiroli, by the Institutional Ethical Committee of SEARCH formed according to the guidelines by the Indian Council for Medical Research. Consent was obtained first at the cluster level in the study villages 15 days before starting the survey. The community leaders (village council leaders and members, school teacher and presidents of microfinance self-help groups) were explained the purpose and scope of the study including the benefits to the villagers (availability of referral care in the clinic of SEARCH and the care through a village clinic). Informed written consent was obtained in vernacular language in a standard format from individual participants after explaining the nature and benefits of the study. The consultation by spine surgeons and rheumatologists and physiotherapists, medications, laboratory investigations, as well as imaging with $\mathrm{X}$-rays and magnetic resonance imaging (MRI) including transport were provided free of cost to the study participants. For those needing surgical interventions, such services were provided at significantly subsidized costs. The CHW discussed these benefits using a printed pamphlet.

\section{RESULTS}

The total population of two villages was 3735 and 2,535 subjects who were $\geqslant 20$ years of age were eligible to participate in the study. Out of this number, 2,259 (89\%) accepted to participate in the study and formed the study sample. Over half of them, 1,247 (55\%) reported having pain in back or extremities at the time of the survey. An invitation to visit the clinic was offered to all of them, and 906 (73\%) attended the village clinics (Figure 1). Among those who did attend the clinic, 22 (2\%) were symptom-free on the day of the clinical examination, and were subsequently excluded; this meant that the final sample size for the clinical attendees was 884 (Table 1).

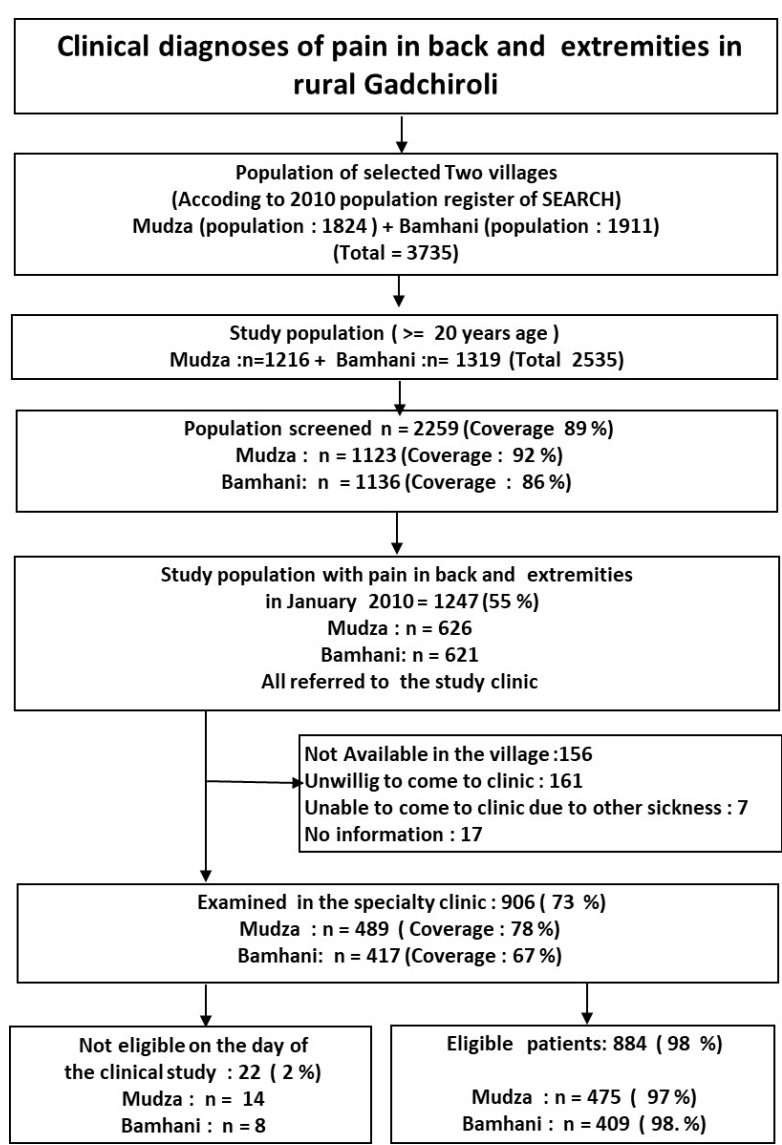

Figure 1. The study flow.

The comparison between attendees and non-attendees of the clinic visit suggested that non-attendees were more commonly younger $(P<0.001)$, men $(P=0.002)$, more literate $(P=0.015)$ and were more likely to be laborers $(P=0.016$; Table 1).

The point prevalence of pain in extremities was 38.4\%; prevalence of arthritis was $12.2 \%$, with osteoarthritis being the commonest disorder (Table 2). Among various sites, osteoarthritis of knee had the highest prevalence (8.9\%). The point prevalence of STR was $28 \%$. Regional STR was more common (24.7\%) than diffuse STR (4.9\%, Table 2). In the regional STR, the prevalence of arthralgia involving knee was $12.2 \%$, shoulder was $7.5 \%$, ankle was $3.6 \%$ while elbow was $3.2 \%$. Among diffuse STR, the prevalence of fibromyalgia was $1.3 \%$. The prevalence of rheumatoid arthritis was $0.4 \%$, spondyloarthropathies was $0.2 \%$, polymyositis was $0.1 \%$ and infective arthritis was $0.2 \%$. None of the patients had gout or acute traumatic arthritis (Table 2).

\section{SEX AND AGE DISTRIBUTION}

The prevalence of arthritis (13.3\% vs $9.7 \%, P=0.007)$ and STR (31.5\% vs $24.3 \%, P<0.001)$ was higher among women than men (Table 3 ). The prevalence increased with advancing age in general (Figure 2). Prevalence of regional STR was about $5 \%$ in the age group of $20-30$ years and increased to $25 \%$ after the age of 40 years. The prevalence of osteoarthritis of knee was less than $5 \%$ until the age of 40 years and increased to $20 \%$ among those $>60$ years of age. 
Table 1. Demographic characteristics of the clinic attendees and non-attendees

\begin{tabular}{|c|c|c|c|}
\hline Characteristic & Clinic attendees $(n=884)$ & Non-attendees $(n=363)$ & $P$ \\
\hline Age; mean \pm standard deviation & $48.5 \pm 15.3$ & $43.1 \pm 14.4$ & $<0.001$ \\
\hline Males; n (\%) & $326(37)$ & $169(47)$ & 0.002 \\
\hline Literate; n (\%) & $420(48)$ & $200(55)$ & 0.015 \\
\hline Married; n (\%) & $845(96)$ & $340(94)$ & 0.156 \\
\hline \multicolumn{4}{|l|}{ Caste; n (\%) } \\
\hline Scheduled caste & $85(10)$ & $37(10)$ & 0.755 \\
\hline Scheduled tribe & $129(15)$ & $51(14)$ & 0.804 \\
\hline Others & $670(76)$ & $275(76)$ & 0.990 \\
\hline \multicolumn{4}{|l|}{ Occupation; n (\%) } \\
\hline Labourer & $351(40)$ & $171(47)$ & 0.016 \\
\hline Farmer & 309 (35) & $133(37)$ & 0.572 \\
\hline Servicemen/woman & $22(2)$ & $11(3)$ & 0.588 \\
\hline Housewife & $98(11)$ & $17(5)$ & $<0.001$ \\
\hline Business & $61(7)$ & $23(6)$ & 0.718 \\
\hline Other & $43(5)$ & $8(2)$ & 0.031 \\
\hline
\end{tabular}

The prevalence of other osteoarthritis and diffuse STR also increased with age but remained close to $5 \%$ in those $>60$ years (Figure 2).

\section{DISCUSSION}

The results of this study show that a third of adults had STR and about one in eight adults had arthritis in the rural population of one of the most underdeveloped districts of India. At the same time, the prevalence of inflammatory and infectious rheumatic disorders was low. Expectedly, the prevalence of rheumatic disorders was higher among women and increased in elderly.

The prevalence of STR in this study (28\%) is higher than that reported from Bhigwan in rural India (5.5\%), ${ }^{11}$ as well as that reported from the Community Oriented Programme for Control of Rheumatic Diseases (COPCORD) studies conducted in the rural areas of other developing countries $(2.3-6.6 \%) .{ }^{20}$ These findings are similar to that reported from studies in China and Lebanon. ${ }^{21,22}$ The prevalence of osteoarthritis (OA) was also higher in the current study (11.4\%) than that reported from the study in Bhigwan (5.8\%). ${ }^{11}$ The prevalence of OA reported in the COPCORD studies from rural areas of other developing countries has ranged from 3.95 to $8.5 \% .^{20}$ The reason for higher prevalence of STR and OA in the present study compared to those reported in other rural areas will need further investigation. Joshi et al had speculated that the higher prevalence of STR and knee OA in rural Indian populations could be due to micro trauma to musculoskeletal tissues from occupational overuse. ${ }^{23}$ As mechanization in farming activities is low in Gadchiroli and farming and non-farming labour activities in this district requires static work postures as well as lifting, carrying, pushing and pulling,the prevalence of OA and STR could be higher than other rural farming populations. Also, psychosocial factors have been implicated as risk factors for STR such as high speed of work, lack of social sup- port, monotonous work and lack of autonomy or control. ${ }^{24}$ Some of these factors may be applicable to the farming and other manual labour activities undertaken by the rural population in Gadchiroli.

The prevalence of rheumatoid arthritis in the current study was $0.4 \%$ which is comparable to that in Bhigwan $(0.54 \%)$ and is comparable to that reported from COPCORD studies in rural regions of other developing countries $(0.28-1 \%){ }^{20}$ The prevalence of ankylosing spondylitis in the current study was $0.2 \%$ while in the COPCORD studies conducted in the rural areas of developing countries it was $0.09-0.26 \%{ }^{20}$ We did not come across any patient with gout or acute traumatic arthritis in the current study. The prevalence of infective arthritis in our study was low (0.2\%) despite the study area being one of the most underdeveloped parts of India. In a study conducted in rural and urban parts of Pune, which is a developed region of India, no cases of infective rheumatic disorders were found. ${ }^{23}$

The findings of high prevalence of STR and OA found in our study is probably also applicable to other rural regions of India, where adults rely heavily on physical labour to earn their livelihood. Given the high prevalence and the need for healthcare services, care for these ailments needs to be provided at the village level in rural areas preferably through the public healthcare system so that the care is provided at minimal costs. As the prevalence of serious rheumatic disorders was low, village level accredited social health activists (ASHAs) in the public healthcare system in India can potentially be used to provide care for this problem. These workers can be trained to diagnose and refer those with serious disorders and provide treatment for the rest. Those with more serious conditions like inflammatory and infectious rheumatic disorders will have to be managed at the level of the Community Health Centres (which typically cater to a population of 100,000 ) or at the district hospitals (typically catering to a population of 1 million or higher) of the public healthcare system. 
Table 2. Point prevalence of rheumatic disorders in the sample and in the population (adjusted for nonattendees)

\begin{tabular}{|c|c|c|c|}
\hline No. & Condition* & Sample prevalence; $\mathrm{n}(\%)$ & Population prevalence ${ }^{\dagger}\left[95 \% \mathrm{Cl}^{\ddagger}\right]$ \\
\hline & Pain in extremities & $615(69.6)$ & $38.4[36.4-40.4]$ \\
\hline \multirow[t]{10}{*}{ I } & Arthritis & $196(22.2)$ & $12.2[10.8-13.5]$ \\
\hline & Osteoarthritis & $183(20.7)$ & $11.4[10.1-12.7]$ \\
\hline & a, Osteoarthritis of knee & $142(16.1)$ & $8.9[7.6-10.0]$ \\
\hline & b, Other osteoarthritis & $41(4.6)$ & $2.6[1.9-3.2]$ \\
\hline & Rheumatoid arthritis & $6(0.7)$ & $0.4[0.1-0.6]$ \\
\hline & Spondyloarthropathies (ankylosing spondylitis) & $3(0.3)$ & $0.2[0.0-0.4]$ \\
\hline & Infective causes & $3(0.3)$ & $0.2[0.0-0.4]$ \\
\hline & $\mathrm{a}, \mathrm{TB} \S$ & $1(0.1)$ & $0.1[0.0-0.1]$ \\
\hline & b, Non TB§ (Pyogenic, Fungal, Viral] & $2(0.2)$ & $0.1[0.0-0.3]$ \\
\hline & Other arthritic disorders & $2(0.2)$ & $0.1[0.0-0.3]$ \\
\hline \multirow[t]{2}{*}{ II } & Other Rheumatic Diseases & $1(0.1)$ & $0.1[0.0-0.1]$ \\
\hline & Polymyositis & $1(0.1)$ & $0.1[0.0-0.1]$ \\
\hline \multirow[t]{19}{*}{ III } & Soft Tissue Rheumatism & $448(50.7)$ & $28[26.1-29.8]$ \\
\hline & Diffuse & $78(8.8)$ & $4.9[4.0-5.8]$ \\
\hline & a, Fibromyalgia & $21(2.4)$ & $1.3[0.8-1.7]$ \\
\hline & b, Others soft tissue pain & $58(6.6)$ & $3.6[2.9-4.5]$ \\
\hline & Regional & $392(44.3)$ & $24.7[22.7-26.3]$ \\
\hline & a, Arthralgia & $368(41.6)$ & $23[21.2-24.7]$ \\
\hline & Shoulder & $120(13.6)$ & $7.5[6.4-8.6]$ \\
\hline & Elbow & $52(5.9)$ & $3.2[2.5-4.0]$ \\
\hline & Wrist & $27(3.1)$ & $1.7[1.2-2.2]$ \\
\hline & Hand & $14(1.6)$ & $0.9[0.5-1.3]$ \\
\hline & Hip & $7(0.8)$ & $0.4[0.2-0.7]$ \\
\hline & Knee & $196(22.2)$ & $12.2[10.9-13.6]$ \\
\hline & Ankle & $57(6.4)$ & $3.6[2.8-4.3]$ \\
\hline & Foot & $22(2.5)$ & $1.4[0.9-1.9]$ \\
\hline & b, Soft Tissue & $38(4.3)$ & $2.4[1.8-3.0]$ \\
\hline & Arm & $10(1.1)$ & $0.6[0.3-0.9]$ \\
\hline & Thigh & $5(0.6)$ & $0.3[0.1-0.5]$ \\
\hline & Calf & $12(1.4)$ & $0.7[0.4-1.1]$ \\
\hline & Foot or toes & $8(0.9)$ & $0.5[0.2-0.8]$ \\
\hline IV & Post-traumatic conditions & $6(0.7)$ & $0.4[0.1-0.6]$ \\
\hline v & Unclassified & $52(5.9)$ & $3.2[2.5-4.1]$ \\
\hline
\end{tabular}

* Conditions are overlapping and not exclusive

$\dagger$ prevalence in the entire population (participants and non-participants)

$\ddagger$ Confidence Interval

$\S$ Tuberculosis

The strengths of this study include a community-based sample, with close to $90 \%$ of population coverage. Additionally, the diagnoses were made by clinical experts. At the same time, the study has several limitations. These include the lack of clinic attendance among the invited residents, which we tried to offset by developing a statistical adjustment. Additionally, the response was less among young males, labourers and literate individuals, possibly causing some selection bias; higher mobility of this group might be the reason for their non-response. The other potential limitation of the study is that those without symptoms of rheumatic diseases at the time of the initial screening survey could have been missed.

\section{CONCLUSIONS}

Our study, conducted in one of the poorest communities of India, shows that STR and arthritis are the commonest rheumatic disorders, while infectious and inflammatory 
Table 3. Sex-wise percentage prevalence of arthritis and soft tissue rheumatism among adults

\begin{tabular}{lccc}
\hline Diagnosis* & Men $\$\left[95 \% \mathrm{Cl}^{\dagger}\right]$ & Women $\$$ \% $\left[95 \% \mathrm{Cl}^{\dagger}\right]$ & $\boldsymbol{P}$ \\
\hline Arthritis & $9.7[8.0,11.6]$ & $13.3[11.4,15.4]$ & 0.007 \\
Osteoarthritis of knee & $6.8[5.4,8.5]$ & $9.7[8.0,11.5]$ & 0.013 \\
Other osteoarthritis & $2.3[1.5,3.3]$ & $2.5[1.7,3.6]$ & 0.716 \\
Soft tissue rheumatism & $24.3[21.7,26.9]$ & $31.5[28.9,34.3]$ & $<0.001$ \\
Regional & $22.7[20.3,25.3]$ & $26.1[23.6,28.7]$ & 0.062 \\
$\quad$ a. Arthralgia & $21.2[18.9,23.8]$ & $24.4[22.0,27.0]$ & 0.071 \\
Diffuse & $2.5[1.7,3.7]$ & $7.1[5.7,8.7]$ & $<0.001$ \\
\hline
\end{tabular}

* Diagnostic categories are overlapping and not exclusive

$\$$ Adjusted for non-participants

$\dagger$ Confidence interval

disorders were rare. The healthcare providers working in rural areas of India need to be trained to manage these disorders. Given the high prevalence of rheumatic disorders, care for this problem needs to be provided at village level through public healthcare system to reduce out of pocket expenditure on the care of these disorders.

\section{ACKNOWLEDGEMENTS}

We thank the people, community health workers, volunteers and leaders of the village Mudza and Bamhani who participated in the study and made all the arrangements. We thank Dr. Rani Bang, SEARCH, Gadchiroli for her support in conceiving and conducting the study. We thank Dr Shital Mohite, Dr Smruti Ramteke and Dr Balkrishna for participating in data collection.

\section{FUNDING}

The study was funded by Sir Dorabji Tata Trust, the Spine Foundation, Mumbai, and SEARCH, Gadchiroli, India.

\section{AUTHORSHIP CONTRIBUTIONS}

Conceived and designed the study: AAB, ATB, SYB, VRJ, MD, SK, RV. Conducted the study: VRJ, SYB, SK, RV, AAB, MD, TY, ATB. Analysed the data: MD, AAB, ATB. Contributed materials / analysis tools: VRJ, SYB, SK, RV. Wrote the draft manuscript: YK. Reviewed the manuscript: ATB.

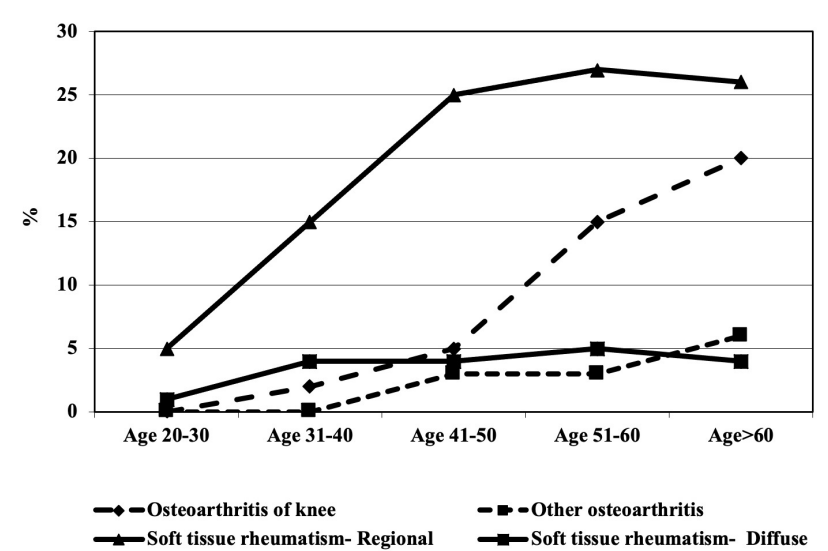

Figure 2. Age-wise population prevalence of soft tissue rheumatism and osteoarthritis.

\section{COMPETING INTERESTS}

The authors completed the Unified Competing Interest form at www.icmje.org/coi_disclosure.pdf (available upon request from the corresponding author) and declare no conflicts of interest.

\section{CORRESPONDENCE TO:}

Dr. Abhay Bang, MD, M.P.H.

Director, SEARCH, Shodhgram, PO Gadchiroli, Maharashtra, India 422605.

Submitted: February 23, 2021 GMT, Accepted: March 16, 2021 GMT 


\section{REFERENCES}

1. Smith E, Hoy DG, Cross M, et al. The global burden of other musculoskeletal disorders: estimates from the Global Burden of Disease 2010 study. Ann Rheum Dis. 2014;73(8):1462-1469. doi:10.1136/annrheumdi $\underline{\mathrm{s}-2013-204680}$

2. Woolf AD, Pfleger B. Burden of major musculoskeletal conditions. Bull World Health Organ. 2003;81(9):646-656

3. Vos T, Flaxman AD, Naghavi M, et al. Years lived with disability (YLDs) for 1160 sequelae of 289 diseases and injuries 1990-2010: a systematic analysis for the Global Burden of Disease Study 2010. Lancet. 2012;380(9859):2163-2196. doi:10.1016/S014 $\underline{0-6736(12) 61729-2}$

4. Cieza A, Causey K, Kamenov K, Hanson SW, Chatterji S, Vos T. Global estimates of the need for rehabilitation based on the Global Burden of Disease study 2019: a systematic analysis for the Global Burden of Disease Study 2019. The Lancet. 2020;396(10267):2006-2017. doi:10.1016/S0140-673 6(20)32340-0

5. Hoy DG, Smith E, Cross M, et al. Reflecting on the global burden of musculoskeletal conditions: lessons learnt from the global burden of disease 2010 study and the next steps forward. Ann Rheum Dis. 2015;74(1):4-7. doi:10.1136/annrheumdis-2014-2053 $\underline{93}$

6. Davatchi F, Tehrani Banihashemi A, Gholami J, et al. The prevalence of musculoskeletal complaints in a rural area in Iran: a WHO-ILAR COPCORD study (stage 1, rural study) in Iran. Clin Rheumatol. 2009;28(11):1267-1274. doi:10.1007/s10067-009-123 $\underline{4-8}$

7. Obregón-Ponce A, Iraheta I, García-Ferrer H, Mejia B, García-Kutzbach A. Prevalence of musculoskeletal diseases in Guatemala, Central America: the COPCORD study of 2 populations. J Clin Rheumatol Pract Rep Rheum Musculoskelet Dis. 2012;18(4):170-174. doi:10.1097/RHU.0b013e318258 $\underline{3803}$

8. Haq SA, Darmawan J, Islam MN, et al. Prevalence of rheumatic diseases and associated outcomes in rural and urban communities in Bangladesh: a COPCORD study. J Rheumatol. 2005;32(2):348-353.
9. Darmawan J, Valkenburg HA, Muirden KD, Wigley RD. Epidemiology of rheumatic diseases in rural and urban populations in Indonesia: a World Health Organisation International League Against Rheumatism COPCORD study, stage I, phase 2. Ann Rheum Dis. 1992;51(4):525-528. doi:10.1136/ard.5 1.4 .525

10. Census of India 2011: Rural Urban Distribution of Population. Accessed June 19, 2019. http://censusindi a.gov.in/2011-prov-results/paper2/data_files/india/Ru ral_Urban_2011.pdf

11. Chopra A, Patil J, Billempelly V, Relwani J, Tandle HS. Prevalence of rheumatic diseases in a rural population in western India: a WHO-ILAR COPCORD Study. J Assoc Physicians India. 2001;49:240-246.

12. Mathew AJ, Chopra A, Thekkemuriyil DV, George E, Goyal V, Nair JB. Impact of musculoskeletal pain on physical function and health-related quality of life in a rural community in south India: A WHO-ILARCOPCORD-BJD India Study. Clin Rheumatol. Published online August 19, 2011. doi:10.1007/s1006 7-011-1824-0

13. Collectorate Gadchiroli. Collectorate, Gadchiroli. Accessed January 4, 2012. http://gadchiroli.nic.in/

14. The Mahatma Gandhi National Rural Employment Guarantee Act 2005. Accessed March 24, 2021. http s://www.nrega.nic.in/netnrega/mgnrega_new/Nreg a home.aspx

15. Aspirational Districts - Overall \& Theme-wise Full Ranks. https://niti.gov.in/sites/default/files/201 9-01/Aspirational_Districts-O

16. Lwanga SK, Lemeshow S. Sample Size Determination in Health Studies: A Practical Manual. World Health Organization; 1991. https://apps.who.in t/iris/handle/10665/40062

17. Singh JA, Solomon DH, Dougados M, et al. Development of classification and response criteria for rheumatic diseases. Arthritis Rheum. 2006;55(3):348-352. doi:10.1002/art.22003

18. Encyclopedia of Epidemiology. SAGE Publications Inc. Published February 7, 2021. Accessed February 8, 2021. https://us.sagepub.com/en-us/nam/encyclopedi a-of-epidemiology/book228431

19. Chapter 3. Comparing disease rates. The BMJ | The BMJ: leading general medical journal. Research. Education. Comment. Accessed February 8, 2021. http s://www.bmj.com/wp-json/wp/v2/posts 
20. Chopra A. The COPCORD world of musculoskeletal pain and arthritis. Rheumatology. Published online July 10, 2013:ket222. doi:10.1093/rh eumatology/ket222

21. Chaaya M, Slim ZN, Habib RR, et al. High burden of rheumatic diseases in Lebanon: a COPCORD study. Int J Rheum Dis. 2012;15(2):136-143. doi:10.1111/j.17 56-185X.2011.01682.X

22. Zeng $\mathrm{Q}$ yu, Zang $\mathrm{C}$ hai, Lin $\mathrm{L}$, et al. Epidemiologic study of soft tissue rheumatism in Shantou and Taiyuan, China. Chin Med J. 2010;123(15):2058-2062.
23. Joshi VL, Chopra A. Is there an urban-rural divide? Population surveys of rheumatic musculoskeletal disorders in the Pune region of India using the COPCORD Bhigwan model. J Rheumatol. 2009;36(3):614-622. doi:10.3899/jrheum.080675

24. Natvig B, Picavet HSJ. The epidemiology of soft tissue rheumatism. Best Pract Res Clin Rheumatol. 2002;16(5):777-793. doi:10.1053/berh.2002.0265 